\title{
Predictors for Uncontrolled Hypertension at Ambulatory Blood Pressure Monitoring (ABPM) in Moroccan Patients: About 516 Cases
}

Abdellatif Ezzouak ${ }^{*}$, Mehdi Badidi

Department of Cardiology Military Hospital Moulay Ismail Meknes-Morocco

$\begin{array}{ll}\text { DOI: } 10.36348 / \text { sjmps.2020.v06i03.006 } & \text { | Received: 07.03.2020 | Accepted: 15.03.2020 | Published: } 27.03 .2020 \\ \text { *Corresponding author: Abdellatif Ezzouak } & \end{array}$

*Corresponding author: Abdellatif Ezzouak

\section{Abstract}

Introduction: Hypertension (HTN) is a major public health problem in the world, responsible for heavy morbidity and cardiovascular mortality, the prevention necessarily involves good control of blood pressure. The factors of bad blood pressure control, apart from medication compliance, are numerous and variable. The aim of our study is to determine the prevalence of uncontrolled HTN and to identify the predictors of poor control of blood pressure. Patients and methods: The study involved 516 hypertensive patients who had been treated for at least six months. We split our sample into two groups according to the blood pressure at the ambulatory blood pressure measurement (ABPM). A multivariate analysis using a binary logistic regression model was performed to determine the factors associated with poor control of blood pressure control. Results: These were 320 men (62\%) and 196 women (38\%), aged $61.5 \pm 9$ years on average. Hypertension was uncontrolled in 260 patients $(50.4 \%)$. In multivariate analysis, we retained as factors associated with poor control of blood pressure: advanced age $(\mathrm{p}=0.001)$, male sex $(\mathrm{p}=0.027)$, monotherapy $(\mathrm{p}=0.02)$, diabetes $(\mathrm{p}=$ $0.03)$, family history of HTN $(\mathrm{p}=0.02)$, high salt diet $(\mathrm{p}=0.004)$ and positive microalbuminuria $(\mathrm{p}=0.01)$. Conclusion: The level of blood pressure control in our sample remains relatively insufficient. This study made it possible to identify the profile or subgroup of patients at risk of poor control of blood pressure, for whom closer monitoring and more vigilant management are necessary.

Keywords: Hypertension, predictors, risk factors, ABPM, uncontrolled, Morocco.

Copyright @ 2020: This is an open-access article distributed under the terms of the Creative Commons Attribution license which permits unrestricted use, distribution, and reproduction in any medium for non-commercial use (NonCommercial, or CC-BY-NC) provided the original author and source are credited.

\section{INTRODUCTION}

Hypertension (HTN) is a major public health problem in the world, responsible for a heavy morbidity and cardiovascular mortality: it multiplies by three the risk of coronary involvement and intermittent claudication, by five the risk of congestive heart failure and by eight that of strokes [1].

In fact, the increase in cardiovascular risk is directly linked to the increase in blood pressure figures in a continuous relationship from $115 / 75 \mathrm{mmHg}$. Therefore, the benefit of antihypertensive therapy is correlated with a drop in blood pressure (BP). Uncontrolled, it could be complicated by serious cardiovascular events [2].

Thus, all the recommendations insist on the importance of taking charge of hypertension and in particular on the good control of blood pressure. However, obtaining a pressure balance is not at all easy in practice and it remains insufficiently controlled according to most of the data in the literature [3].
Ambulatory blood pressure measurement (ABPM) is an effective means in the therapeutic assessment of blood pressure balance in hypertensive patients. The objective of this work is to assess the level of blood pressure control at ABPM and to identify the predictive factors associated with poor control of blood pressure.

\section{Patients And Methods}

It is a cross-sectional study with prospective, descriptive and analytical data collection, carried out between January 1, 2015 and June 30, 2017 (30 months).

We consecutively included 516 hypertensive patients treated and followed up for at least six months before the study period, and who were regularly taking their antihypertensive drugs (good drug compliance), using the simple Girerd quiz for the evaluation of this observance [4]. 
All patients benefited from an ABPM using a device validated by international authorities. The threshold used for a controlled HTN was a BP $<130 / 80$ $\mathrm{mmHg}$ on all of the 24-hour averages. The patients were thus divided into two groups according to whether or not they were controlled.

Non-dippers were defined as those with less than $10 \%$ decrease in nighttime pressure compared to daytime averages or with a nocturnal elevation of BP.

Several parameters were studied: sociodemographic (age, sex, educational level); other associated cardiovascular risk factors (diabetes, overweight / obesity, dyslipidemia, active smoking, physical inactivity and coronary inheritance), microalbuminuria, BP averages (24h, day and night), family history of hypertension, number of antihypertensive drugs used, the therapeutic classes prescribed and the sodium intake which was objectively quantified from a 24hour urinary ionogram. The family history of hypertension was defined as the occurrence of HTN in one or both parents at an age less than 50 years.

\section{Statistical ANALYSIS}

The qualitative variables were expressed as a percentage and the quantitative variables as an average (standard deviation).

In order to determine the factors significantly linked to an uncontrolled HTN, a binary logistic regression analysis was carried out by choosing as a result the dichotomous variable "to have an uncontrolled hypertension". The model only included factors statistically linked to poor control of blood pressure in the univariate analysis.

We analyzed data using SPSS version 21. A P value $<0.05$ was considered statistically significant.

\section{RESULTS}

These were 318 men (61.6\%) and 198 women $(38.4 \%)$, aged $61.2 \pm 9$ years on average, with extremes ranging from 34 to 83 years. For the educational level, 178 cases $(34.5 \%)$ were illiterate, while 232 cases (45\%) had an average educational level, and only 106 cases $(20.5 \%)$ were able to have a higher university level.

The other associated cardiovascular risk factors were diabetes in 196cases (38\%), active chronic smoking in 118 cases $(22.9 \%)$, physical inactivity in 374 cases (72.4\%), obesity in 206 cases ( 39.9\%), dyslipidemia in 74 cases $(14.3 \%)$ and a family history of HTN was noted in 192 cases (37.2\%). Microalbuminuria was positive in 94 cases $(18.2 \%)$.

Hypertension was controlled in 260 patients $(50.4 \%)$. The average nycthemeral was $138.3 \pm 16$ $\mathrm{mmHg}$ for systolic BP (SBP) and $79.8 \pm 10.3 \mathrm{mmHg}$ for diastolic BP (DBP). The diurnal and nocturnal averages were $142.1 \pm 17.5 \mathrm{mmHg}$ and $133.6 \pm 15.7$ $\mathrm{mmHg}$ for SBP respectively; $82.2 \pm 11.6$ and $74.5 \pm$ $10.8 \mathrm{mmHg}$ for DBP. The antihypertensive protocol used was monotherapy in 174 cases $(33.7 \%)$, dual therapy in 234 cases $(45.3 \%)$, triple therapy or more in 108 cases $(20.9 \%)$. Fifty-one percent of patients were on calcium channel blockers, $49 \%$ on converting enzyme inhibitors, $39 \%$ on angiotensin II receptor blockers, $37 \%$ on diuretics and $12 \%$ on $\beta$-blockers. Sodium intake was more than $6 \mathrm{~g}$ in 406 cases (78.7\%).

Regarding the search for predictive factors of poor blood pressure control, multivariate analysis by binary logistic regression emerged as factors: advanced age, male sex, diabetes, family history of hypertension, monotherapy, microalbuminuria and the deviation from the salt diet.

Predictors of uncontrolled HTN

\begin{tabular}{|c|c|c|c|c|}
\hline variables & \multicolumn{2}{|c|}{ Uncontrolled HTN } & \multirow[t]{2}{*}{ OR (95\%) } & \multirow[t]{2}{*}{$\mathbf{p}$} \\
\hline & Yes & No & & \\
\hline Age (Average) & 64,41 & 58,64 & $0,924(0,89-0,95)$ & 0,001 \\
\hline $\begin{array}{l}\text { Sex } \\
\text { Male } \\
\text { Feminine }\end{array}$ & $\begin{array}{l}194(61 \%) \\
66(33,3 \%)\end{array}$ & $\begin{array}{c}124(39 \%) \\
132(66,7 \%)\end{array}$ & $2,41(1,10-5,26)$ & 0,027 \\
\hline $\begin{array}{l}\text { Educational level } \\
\text { Illiterate } \\
\text { intermediate } \\
\text { superior }\end{array}$ & $\begin{array}{c}84(47,2 \%) \\
126(54,3 \%) \\
50(47,2 \%)\end{array}$ & $\begin{array}{c}94(52,8 \%) \\
106(45,7 \%) \\
56(52,8 \%)\end{array}$ & $\begin{array}{c}1 \\
0,75(0,39-1,44) \\
0,99(0,50-1,97)\end{array}$ & $\begin{array}{l}\mathbf{0 , 3 8} \\
\mathbf{0 , 8 1}\end{array}$ \\
\hline $\begin{array}{l}\text { Diabetes mellitus } \\
\text { Yes } \\
\text { No }\end{array}$ & $\begin{array}{l}136(69,4 \%) \\
124(38,7 \%)\end{array}$ & $\begin{array}{c}60(30,6 \%) \\
196(61,25 \%)\end{array}$ & $2,14(1,06-4,32)$ & $\mathbf{0 , 0 3}$ \\
\hline $\begin{array}{l}\text { Dyslipidemia } \\
\text { Yes } \\
\text { No }\end{array}$ & $\begin{array}{c}38(51,4 \%) \\
220(52,3 \%)\end{array}$ & $\begin{array}{c}36(48,6 \%) \\
220(47,7 \%)\end{array}$ & $1,04(0,52-2,09)$ & 0,89 \\
\hline
\end{tabular}


Abdellatif Ezzouak \& Mehdi Badidi; Saudi J Med Pharm Sci, March., 2020; 6(3): 291-296

\begin{tabular}{|c|c|c|c|c|}
\hline $\begin{array}{l}\text { Weight status } \\
\text { Normal } \\
\text { Overweight } \\
\text { Obesity }\end{array}$ & $\begin{array}{r}44(44,9 \%) \\
102(48,1 \%) \\
114(55,3 \%)\end{array}$ & $\begin{array}{c}54(55,1 \%) \\
110(51,9 \%) \\
92(44,7 \%)\end{array}$ & $\begin{array}{c}1 \\
1,52(0,76-3,01) \\
1,33(0,77-2,30)\end{array}$ & $\begin{array}{l}\mathbf{0 , 2 3} \\
\mathbf{0 , 2 9}\end{array}$ \\
\hline $\begin{array}{l}\text { Sedentary lifestyle } \\
\text { Yes } \\
\text { No }\end{array}$ & $\begin{array}{c}180(48,1 \%) \\
80(56,3 \%)\end{array}$ & $\begin{array}{c}194(51,9 \%) \\
62(43,7 \%)\end{array}$ & $1,39(0,80-2,41 \%)$ & 0,24 \\
\hline $\begin{array}{l}\text { Family history of HTN } \\
\text { Yes } \\
\text { No }\end{array}$ & $\begin{array}{l}134(69,8 \%) \\
126(38,9 \%) \\
\end{array}$ & $\begin{array}{c}58(30,2 \%) \\
198(61,1 \%) \\
\end{array}$ & $3,16(1,54-6,49)$ & $\mathbf{0 , 0 2}$ \\
\hline $\begin{array}{l}\text { Smoking } \\
\text { Yes } \\
\text { No } \\
\end{array}$ & $\begin{array}{c}78(66,1 \%) \\
182(45,7 \%)\end{array}$ & $\begin{array}{c}40(33,8 \%) \\
216(54,2 \%)\end{array}$ & $2,18(0,86-5,50)$ & 0,09 \\
\hline $\begin{array}{l}\text { Salt } \\
<6 \mathrm{~g} \\
6-12 \mathrm{~g} \\
>12 \mathrm{~g}\end{array}$ & $\begin{array}{c}38(34,5 \%) \\
102(41,5 \%) \\
100(70,4 \%)\end{array}$ & $\begin{array}{c}72(65,5 \%) \\
144(58,5 \%) \\
40(28,6 \%)\end{array}$ & $\begin{array}{c}1 \\
3,47(1,50-8,03) \\
4,74(1,74-12,86)\end{array}$ & $\begin{array}{l}\mathbf{0 , 0 0 4} \\
\mathbf{0 , 0 0 2}\end{array}$ \\
\hline $\begin{array}{l}\text { Microalbuminuria } \\
\text { Yes } \\
\text { No }\end{array}$ & $\begin{array}{c}72(76,6 \%) \\
188(44,5 \%)\end{array}$ & $\begin{array}{c}22(23,4 \%) \\
234(55,5 \%)\end{array}$ & $4,07(1,68-10,65)$ & $\mathbf{0 , 0 1}$ \\
\hline $\begin{array}{l}\text { Number of drugs } \\
\text { Monotherapy } \\
\text { Dual therapy } \\
\text { Triple therapy or more }\end{array}$ & $\begin{array}{c}140(80,4 \%) \\
94(40,2 \%) \\
26(24,1 \%) \\
\end{array}$ & $\begin{array}{c}34(19,6 \%) \\
140(59,8 \%) \\
82(75,9 \%)\end{array}$ & $\begin{array}{c}1 \\
0,34(0,13-0,88) \\
0,07(0,02-0,22)\end{array}$ & $\begin{array}{l}\mathbf{0 , 0 2} \\
\mathbf{0 , 0 0 1}\end{array}$ \\
\hline
\end{tabular}

\section{DiscUSSION}

HTN is a public health problem because of its frequency and the need for lifelong medication monitoring and treatment, and because of its vascular complications. Numerous studies have shown that HTN remains insufficiently screened, treated and controlled, despite the iterative recommendations of various learned societies on the proper management of HTN $[5,6]$.

Treated but inadequately controlled HTN could still be complicated by serious cardiovascular events [7]. Therefore, controlling blood pressure figures is important in reducing cardiovascular risk. Each fall in SBP by $10 \mathrm{mmHg}$ reduces the risk of cardiovascular events by 11 to $15 \%$ [8]. Thus, the benefits of antihypertensive treatment are correlated with the drop in blood pressure figures.

Compared with the clinical measurement of BP, $\mathrm{ABPM}$ is an effective and reliable means for assessing BP control in hypertensive patients. It makes it possible to obtain a large number of measurements in the usual conditions of life, to determine its variations during the nocturnal, to eliminate the "white coat " effect and to diagnose masked HTN, and therefore it allows to better estimate the cardiovascular risk of each patient.
Few studies have focused on evaluating the control of ABPM treated hypertensives, making any comparisons difficult.

Despite this methodological difference used (assessment by ABPM or clinical measurement), numerous studies have always revealed that HTN is very often poorly controlled [9-16]. In our study, almost one in two patients had the BP goal. However, the frequency of controlled hypertension varies from country to country.

Thus, the prevalence of controlled hypertension according to countries: it varies from $19.9 \%$ in China [9], 28.7\% in Portugal [10], 32.2\% in Greece [11], $50 \%$ in France [12], 53.1\% in the United States [13], 72.4\% in Canada [14], 46\% in Burkina Faso [15] and $31 \%$ in Algeria [16].

Our study showed that the uncontrolled hypertensive patients were older, more frequently male, diabetic, with a family history of hypertension, most often on monotherapy, adopting a hypersodium diet and having a positive microalbuminuria.

Determining the factors of poor HTN control is important in order to identify the profile of patients at risk of uncontrolled BP in order to better manage them. Our study showed that the uncontrolled BP subjects were older and more frequently male. This could be 
explained by more marked arterial stiffness in older men [17]. In addition, HTN in advanced age is most often pure systolic, difficult to control by current antihypertensive drugs which preferentially reduce DBP by acting mainly on peripheral arterial resistance. All the more, systolic-diastolic hypertension in the elderly is often transformed into pure systolic HTN under treatment.

Similarly, antihypertensive monotherapy was also a factor in poor control of BP in our study. In fact, whatever the therapeutic class prescribed, monotherapy was associated with a very poor level of BP control: almost a third of our hypertensive patients were on monotherapy, of which only $19.6 \%$ had controlled HTN.

This relatively high rate of monotherapy patients $(33.7 \%)$ could be largely explained by a very important concept in the management of chronic diseases: therapeutic inertia, defined for the first time in 2001 by Phillips et al. as the failure of the doctor to initiate or increase treatment when indicated [18], releasing several soft reasons " soft excuses ", such as: suspicion of the white coat effect, deviation from the diet, no taking the antihypertensive agent in the morning, fear of side effects by increasing the treatment, etc., while it really reflects the practitioner's weak adherence to the recommendations or the lack of information or organization to reach the therapeutic targets. The goal in the management of HTN is to reach the BP objective regardless of the number of drugs used. Recent international recommendations clearly show that in the majority of hypertensive patients, monotherapy would not be sufficient and that bi or even triple therapy would be essential [19]. In a meta-analysis of more than 40 studies, a greater reduction in BP was obtained by adding a second antihypertensive drug than doubling the dose of monotherapy [20]. Thus, fixed dual-dose first-line dual therapies reduced BP more, especially grade 2 or 3 hypertension, than a single class at full dose [21-23].

The association of HTN and diabetes is frequent: almost $75 \%$ of type 2 diabetics are hypertensive, and $15 \%$ of hypertensive patients are diabetic [24]. Our study showed a high prevalence of diabetes in hypertensive patients: almost one in three hypertensive drugs patients had mainly type 2 diabetes.

Many studies have reported that HTN is more difficult to control in diabetics. In the ASCOT-BPLA study, diabetes was an independent factor in hypertension resistant to triple therapy, with a risk increased by more than $69 \%$ compared to non-diabetics [25]. Even within the diabetic population, the impact of the glycemic balance on the control of HTN has been proven $[8,25,26]$.
The UKPDS study showed that better BP control reduced cardiovascular morbidity and mortality by $24 \%$, deaths by $32 \%$, strokes by $44 \%$ and microangiopathy by $37 \%$. In comparison, strict glycemic control made it possible to reduce morbidity and mortality by $12 \%$ and microangiopathy by $25 \%$ [8]. Good BP control would be more important than good blood sugar control in hypertensive type 2 diabetics.

In our work, it seems quite logical that microalbuminuria stood out as a risk factor for poor blood pressure balance. Indeed, it can be the direct consequence of poorly controlled hypertension as it can aggravate and maintain a preexisting hypertension by the development of a chronic organic kidney disease. It is an independent cardiovascular risk factor and an early marker of renal complications in the hypertensive patient.

Through several studies, the rate of microalbuminuria is positively correlated at the BP, diastolic and above all systolic level, with correlation coefficients generally more powerful with ABPM than with clinical measurement. In addition, hypertensive " no-dippers " have a higher microalbuminuria than hypertensive " dippers " [27].

Finally, it seems obvious that non-compliance with the sodium diet is correlated with poor BP control. This correlation was even more powerful when switching to excessive daily consumption of more than $10 \mathrm{~g}$.

\section{CONCLUSION}

The level of blood pressure control in our sample remains relatively insufficient. This study made it possible to identify the profile or subgroup of patients at risk of poor control of blood pressure, for whom closer monitoring and more vigilant management are necessary.

\section{REFERENCES}

1. Organisation Mondiale de la Santé. (2013). Panorama mondial de l'Hypertension artérielle, Rapport : journée mondiale de la santé OMS 2013.

2. Plouin, P. F., Chatelier, G., Pagny, J. Y., \& Lang, T. (1986). Hypertension artérielle (Épidémiologie, hémodynamique et physiopathologie. Stratégie de l'exploration et de la prise en charge). Encycl Med Chir (Paris France) Coeur-Vaisseaux, 11302, 112.

3. Blacher, J., Halimi, J. M., Hanon, O., Mourad, J. J., Pathak, A., Schnebert, B., \& Girerd, X. (2013). Prise en charge de l'hypertension artérielle de l'adulte. Recommandations 2013 de la Société française d'hypertension artérielle. La Presse Médicale, 42(5), 819-825. 
4. Girerd, X., Hanon, O., Anagnostopoulos, K., Ciupek, C., \& Mourad, J. J. (2001). Evaluation de l'observance du traitement antihypertenseur par un questionnaire: mise au point et utilisation dans un service spécialisé. La Presse médicale (1983), 30(21), 1044-1048.

5. Giuseppe, M. (2013). ESH/ESC Guidelines for the management of arterial hypertension: The Task Force for the management of arterial hypertension of the European Society of Hypertension (ESH) and of the European Society of Cardiology (ESC) Journal of Hypertension, 31:1281-1357

6. Yaméogo, N. V., Kagambèga, L. J., Millogo, R. C. G., Kologo, K. J., Yaméogo, A. A., Mandi, G. D., ... \& Zabsonré, P. (2013, February). Facteurs associés à un mauvais contrôle de la pression artérielle chez les hypertendus noirs africains: étude transversale de 456 hypertendus burkinabé. In Annales de Cardiologie et d'Angéiologie (Vol. 62, No. 1, pp. 38-42). Elsevier Masson.

7. Mozaffarian, D.(2015). Heart disease and stroke statistics -2015 update: a report from the American Heart Association. Circulation, 131:e29-e322.

8. UK Prospective Diabetes Study Group. (1998). Tight blood pressure control and risk of macrovascular and microvascular complications in type 2 diabetes: UKPDS 38. BMJ: British Medical Journal, 317(7160), 703.

9. Wang, Z., Wu, Y., Zhao, L., Li, Y., Yang, J., \& Zhou, B. (2004). Trends in prevalence, awareness, treatment and control of hypertension in the middle-aged population of China, 19921998. Hypertension research, 27(10), 703-709.

10. De, M. M., Lima, M. J., Silva, A. O., Alcântara, P., Ramalhinho, V., \& Carmona, J. (2007). Prevalence, awareness, treatment and control of hypertension in Portugal. The PAP study. Revista portuguesa de cardiologia: orgao oficial da Sociedade Portuguesa de Cardiologia= Portuguese journal of cardiology: an official journal of the Portuguese Society of Cardiology, 26(1), 21-39.

11. Efstratopoulos, A. D., Voyaki, S. M., Baltas, A. A., Vratsistas, F. A., Kirlas, D. E. P., Kontoyannis, J. T., ... \& Vasilakis, E. A. (2006). Prevalence, awareness, treatment and control of hypertension in Hellas, Greece: the Hypertension Study in General Practice in Hellas (HYPERTENSHELL) national study. American journal of Hypertension, 19(1), 53-60.

12. Mourad, J. J., \& Girerd, X. (2012). Objective for 2015: $70 \%$ of treated and controlled hypertensive patients. Seven key points to reach this goal in practice. A joint call for action of the French League Against Hypertension and the French Society of Hypertension. Journal des maladies vasculaires, 37(6), 295-299.
13. Hajjar, I., \& Kotchen, T. A. (2003). Trends in prevalence, awareness, treatment, and control of hypertension in the United States, 19882000. Jama, 290(2), 199-206.

14. Joffres, M. R., Hamet, P., Rabkin, S. W., Gelskey, D., Hogan, K., \& Fodor, G. (1992). Prevalence, control and awareness of high blood pressure among Canadian adults. Canadian Heart Health Surveys Research Group. CMAJ: Canadian Medical Association Journal, 146(11), 1997.

15. Yaméogo, N. V., Kagambèga, L. J., Millogo, R. C. G., Kologo, K. J., Yaméogo, A. A., Mandi, G. D., .. \& Zabsonré, P. (2013, February). Facteurs associés à un mauvais contrôle de la pression artérielle chez les hypertendus noirs africains: étude transversale de 456 hypertendus burkinabé. In Annales de Cardiologie et d'Angéiologie (Vol. 62, No. 1, pp. 38-42). Elsevier Masson.

16. Mesli, M. F., Raïah, M., Mohammedi, B., \& Dida, A. (2015, February). Facteurs associés à un mauvais contrôle tensionnel chez 253 hypertendus traités. In Annales de Cardiologie et d'Angéiologie (Vol. 64, No. 1, pp. 32-38). Elsevier Masson.

17. Safar, M. E., Levy, B. I., \& Struijker-Boudier, H. (2003). Current perspectives on arterial stiffness and pulse pressure in hypertension and cardiovascular diseases. Circulation, 107(22), 2864-2869.

18. Phillips, L.S.(2001). Clinical inertia. Ann Intern Med, 135:825-34

19. Mancia, G., De Backer, G., Dominiczak, A., Cifkova, R., Fagard, R., Germano, G., ... \& Narkiewicz, K. (2007). 2007 Guidelines for the management of arterial hypertension: The Task Force for the Management of Arterial Hypertension of the European Society of Hypertension (ESH) and of the European Society of Cardiology (ESC). European heart journal, 28(12), 14621536.

20. Wald, D. S., Law, M., Morris, J. K., Bestwick, J. P., \& Wald, N. J. (2009). Combination therapy versus monotherapy in reducing blood pressure: meta-analysis on 11,000 participants from 42 trials. The American journal of medicine, 122(3), 290-300.

21. Mancia, G., Laurent, S., Agabiti-Rosei, E., Ambrosioni, E., Burnier, M., Caulfield, M. J., ... \& Erdine, S. (2009). Reappraisal of European guidelines on hypertension management: a European Society of Hypertension Task Force document. Blood pressure, 18(6), 308-347.

22. Krause, T., Lovibond, K., Caulfield, M., McCormack, T., \& Williams, B. (2011). Management of hypertension: summary of NICE guidance. Bmj, 343, d4891.

23. Daskalopoulou, S. S., Khan, N. A., Quinn, R. R., Ruzicka, M., McKay, D. W., Hackam, D. G., ... \& Dawes, M. (2012). The 2012 Canadian 
hypertension education program recommendations for the management of hypertension: blood pressure measurement, diagnosis, assessment of risk, and therapy. Canadian Journal of Cardiology, 28(3), 270-287.

24. Katsumori, K., Wasada, T., Kuroki, H., Arii, H., Saeki, A., Aoki, K., ... \& Omori, Y. (1995). Prevalence of macro-and microvascular diseases in non-insulin-dependent diabetic and borderline glucose-intolerant subjects with insulin resistance syndrome. Diabetes research and clinical practice, 29(3), 195-201.
25. Leitao, C. B., Canani, L. H., Silveiro, S. P., \& Gross, J. L. (2007). Ambulatory blood pressure monitoring and type 2 diabetes mellitus. Arquivos brasileiros de cardiologia, 89(5), 347.

26. Locatelli, F., Del Vecchio, L., Pozzoni, P., D'Amico, M., \& Andrulli, S. (2005). Is it the agent or the blood pressure level that matters for renal and vascular protection in chronic nephropathies?. Kidney International, 67, S15-S19.

27. Bianchi, S. (1994). Diurnal variation of blood pressure and microalbulinuria in essential hypertension. Am J Hypertens, 7:23-9. 